\title{
NUMERICAL THERMAL ANALYSIS OF A CAR BRAKING SYSTEM
}

\author{
Patryk Różyło ${ }^{1}$ \\ 1 Lublin University of Technology, Nadbystrzycka 36, 20-618 Lublin, e-mail: p.rozylo@pollub.pl
}

Received: 2017.04.07

Accepted: 2017.05.02

Published: 2017.06.01

\begin{abstract}
The study involved performing a numerical thermal analysis of selected components in a car braking system. The primary goal of the study was to determine the regions which are most susceptible to variations in temperature, and to determine the degree of thermal impact upon them. The analysis was performed using the Abaqus environment. The examined components of the braking system were made of materials reflecting mechanical properties of the real subassemblies. The FEM analysis enabled determination of the distribution of temperature in the system with respect to the properties of the investigated materials and applied boundary conditions.
\end{abstract}

Keywords: Abaqus, braking system, numerical analysis, temperature distribution.

\section{INTRODUCTION}

The impact of temperature on components of machines and mechanisms is a common problem these days. Complex thermal processes are a frequent cause of undesired phenomena occurring inside overheated subassemblies. The excessive impact of temperature on particular components of machinery can have a negative effect, leading to the occurrence of regions with permanent plasticization due to high temperatures, resulting in microcracks or reduced strength. Problems related to structural effort due to thermal processes can be gradually eliminated thanks to the use of other kinds of materials. In the automotive industry, damaging thermal phenomena which occur, among others, in braking systems are connected to high forces generated by pressure transmitted to the pads, causing rapid braking of the disks. In order to reduce the degree of heat generated in such processes, ventilated disks are used. Owing to a number of holes, such disks cool faster than traditional disks. In addition to this, the heat generated at braking can also be reduced using ceramic and composite pads. Advanced friction materials are often used in coupled and dynamics analysis $[3,5,7 \div 9]$.
The key motivation behind conducting studies on material effort due to overheating stems from the need to reduce the degree of wear caused by friction combined with high temperatures. Friction in braking processes is the main cause of

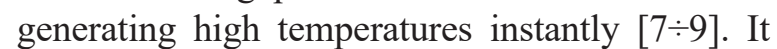
is fundamental that the results of studies on these phenomena be also applied to the ways of efficient cooling of braking system components. Coupled thermal phenomena have been described in the publications $[2,3,5,6,10 \div 12]$. Given the fact that there are few research studies which focus on the investigated problem, it seems necessary to investigate thoroughly the complex problem of braking. The most popular are ventilated disks which have holes or reduced volume resulting from removing material inside the centre of the disk. These innovative solutions enable faster cooling of the disks, yet due to thinner braking surfaces, they usually cause faster heating. Older disks, non-ventilated and solid over the entire element, have one big advantage - they heat more slowly than ventilated disks, yet they are poor at carrying the heat away. Excessive heating and cooling are undesired in machinery operation, however there is no rule concerning the choice of a disk type. Examples of widely used brake disks are shown in Figure 1 [4]. 


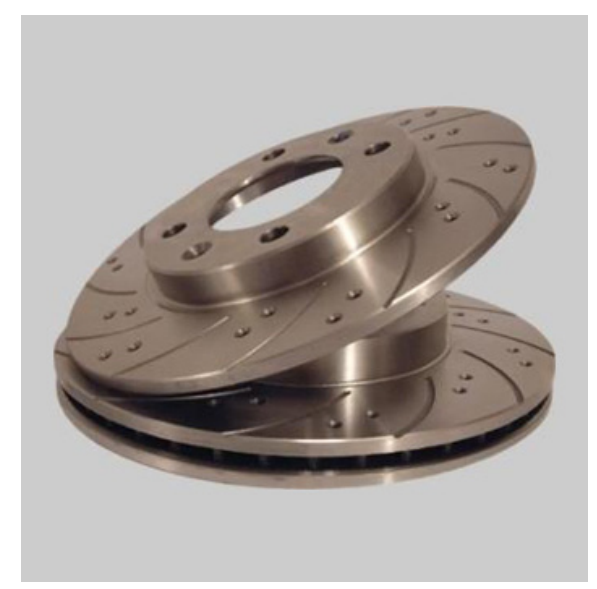

Fig. 1. Example of a car brake disk

\section{MATERIALS AND METHODS}

The simulations were performed on a numerical model of a fragment of a car braking system. The test object comprised a disk and two brake pads. The prepared test specimens were to ensure a sufficient unit to investigate the braking process of the disk at a specific speed due to symmetric pressure by the pads. The disk was made of highcarbon steel $41 \mathrm{Cr} 4$. The brake pads were designed based on the material data of a standard friction material. The parameters describing the material steel and composite pads were related solely to their thermal properties, as well as density. The table 1 shows the selected parameters used in the simulation of the braking process [5].

The figure 2 shows the geometrical model of the prepared fragment of the braking system, i.e. the disk and the pad.

The numerical model of the fragment of the braking system consists of a disk and symmetrically arranged two brake pads. In order to reflect the real work of the mechanism, only elements that were necessary for performing a basic FEM analysis were designed. The aim of the numerical simulation was to reflect the real behavior of the fragment of the braking system during a specified period of time. It was assumed that the initial operating temperature of the system was $0^{\circ} \mathrm{C}$. The numerical analysis was performed based on a

Table 1. Material properties of the components

\begin{tabular}{|c|c|c|}
\hline Parameter & Disk & Pad \\
\hline Density & $7100\left[\mathrm{~kg} / \mathrm{m}^{3}\right]$ & $2450\left[\mathrm{~kg} / \mathrm{m}^{3}\right]$ \\
\hline Specific heat & $500\left[\mathrm{~J} / \mathrm{kg}^{*} \mathrm{~K}\right]$ & $770\left[\mathrm{~J} / \mathrm{kg}^{*} \mathrm{~K}\right]$ \\
\hline Conductivity & $51\left[\mathrm{~W} / \mathrm{m}^{*} \mathrm{~K}\right]$ & $1.6\left[\mathrm{~W} / \mathrm{m}^{*} \mathrm{~K}\right]$ \\
\hline
\end{tabular}

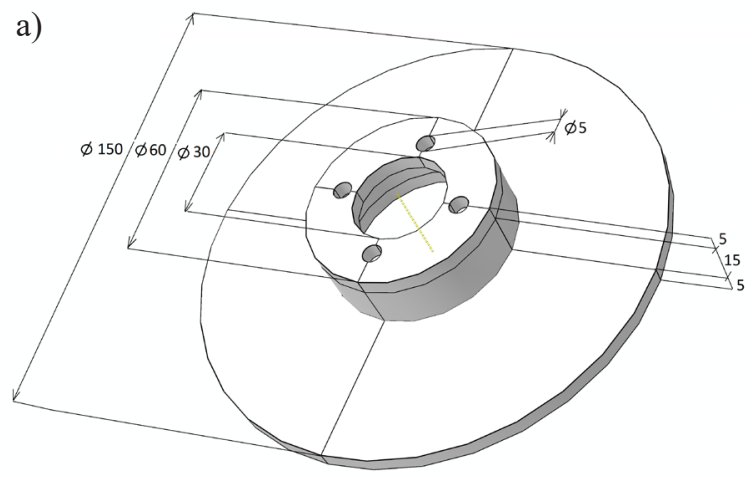

b)

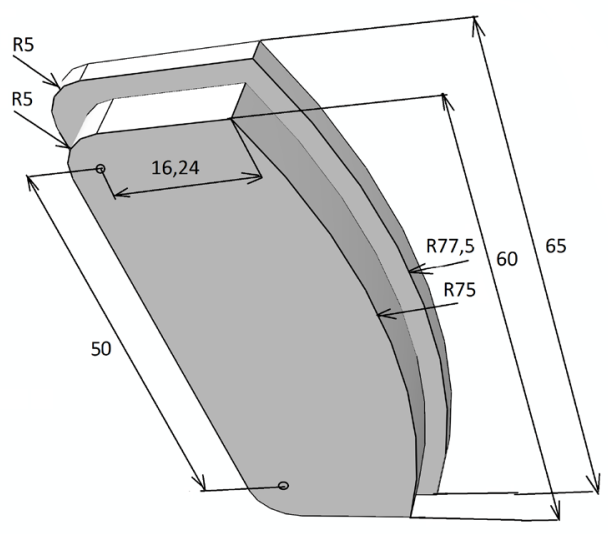

Fig. 2. Test specimen and its geometrical parameters: a) model of the disk, b) model of the brake pad

dynamic problem related to the effect of displacement and temperature. The time of simulation was set to 3 seconds. During this time, the disk makes 60 revolutions at braking, which results from the approximate initial speed of the vehicle $(135.6 \mathrm{~km} / \mathrm{h})$, assuming that the tire has a mean size of 15 inches and a mean diameter of approximately $600 \mathrm{~mm}$. The coefficient of friction applied in the FEM calculations was set to 0.35 . As a result of correctly defined boundary conditions to pad displacement of both the pads and the disk in axes $\mathrm{X}$ and $\mathrm{Z}$, the problem was correctly realized regarding the essential relationship of the

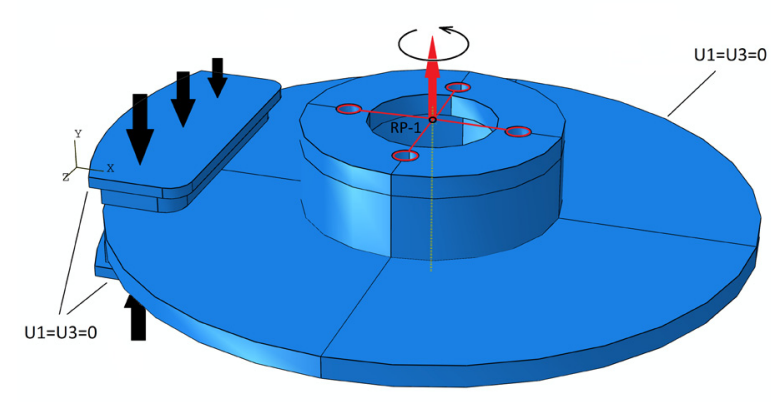

Fig. 3. Boundary conditions 


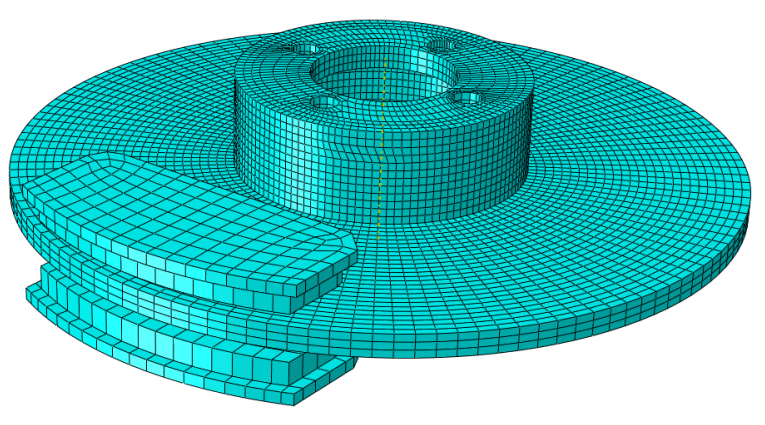

Fig. 4. Finite Element mesh

elements relative to the Y-axis. The outer surfaces of the pads were subjected to the total pressure of $2 \mathrm{MPa}$, causing a constant pressure with the applied value on both planes of the disk. The holes in the disk were coupled with a point of reference located in the centerline of the disk. The coupling enabled describing the disk by a rotational speed of 125.6 radians per second, which amounts to 1200 revolutions per minute, i.e., 20 revolutions per second. The displacement of the brake pads relative to the Y-axis and the definition of other boundary conditions enabled reflecting the real braking process. The numerical model with the declared boundary conditions and suitable position in space is shown in Figure 3.

The discretization of the model was performed in several stages. First, it was necessary to select the adequate type of mesh element for the given dynamic thermal analysis. As a result, a linear hexagonal element type was defined; it was marked as C3D8RT with reduced integration for performing analyses of temperature and displacement $[1$, 13]. The technique of reduced integration has a positive effect on the FEM results, as it excludes false modes of deformation in the investigated structures. The next stage involved determining a suitable mesh density and dividing elements into partitions in order to generate a symmetrically distributed mesh with correct geometry. Due to the dynamic nature of the problem at hand, the discretization process is of vital importance, as described analyses require preparation of a highly accurate FE mesh. The total number of finite ele-
TEMP
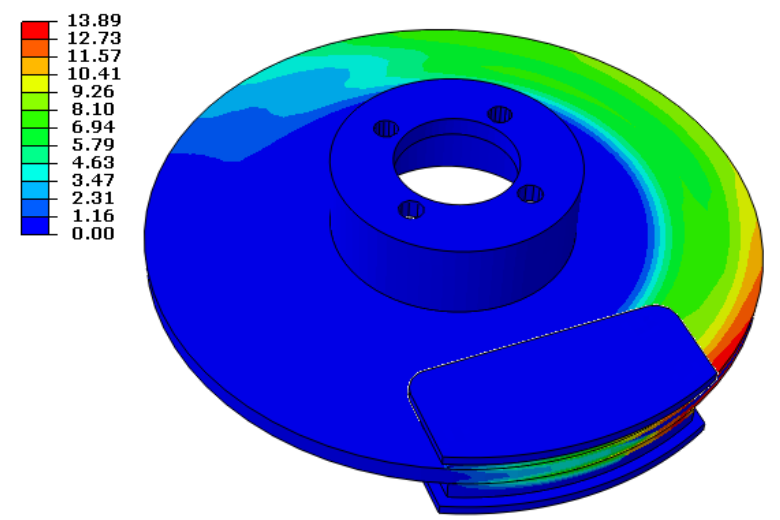

c)

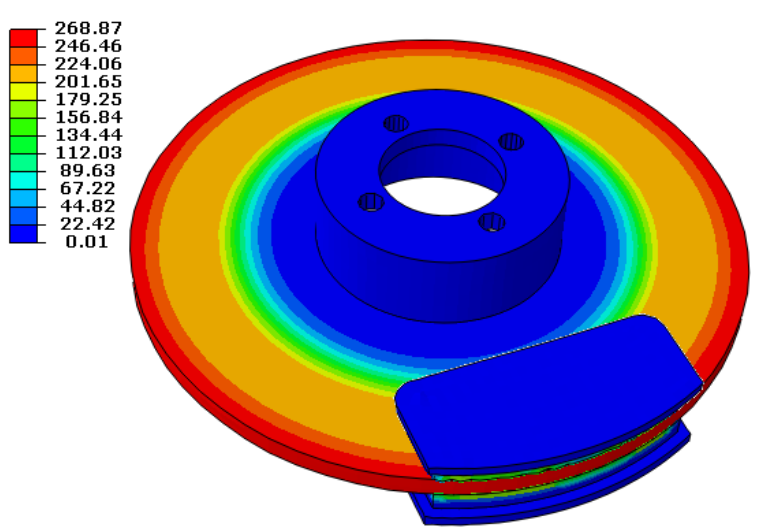

TEMP

b)

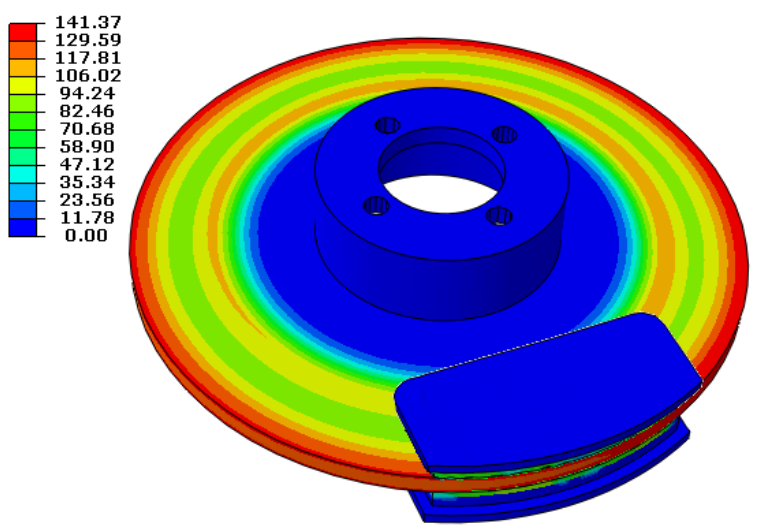

TEMP

d)

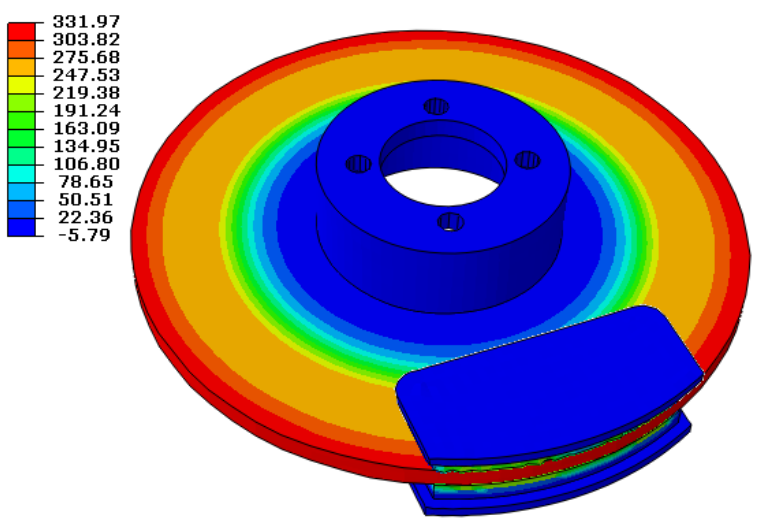

Fig. 5. Distribution of the temperatures in the braking system: a) after $0.05 \mathrm{~s}$ of braking, b) after $1 \mathrm{~s}$ of braking, c) after $2 \mathrm{~s}$ of braking d) after $3 \mathrm{~s}$ of braking 


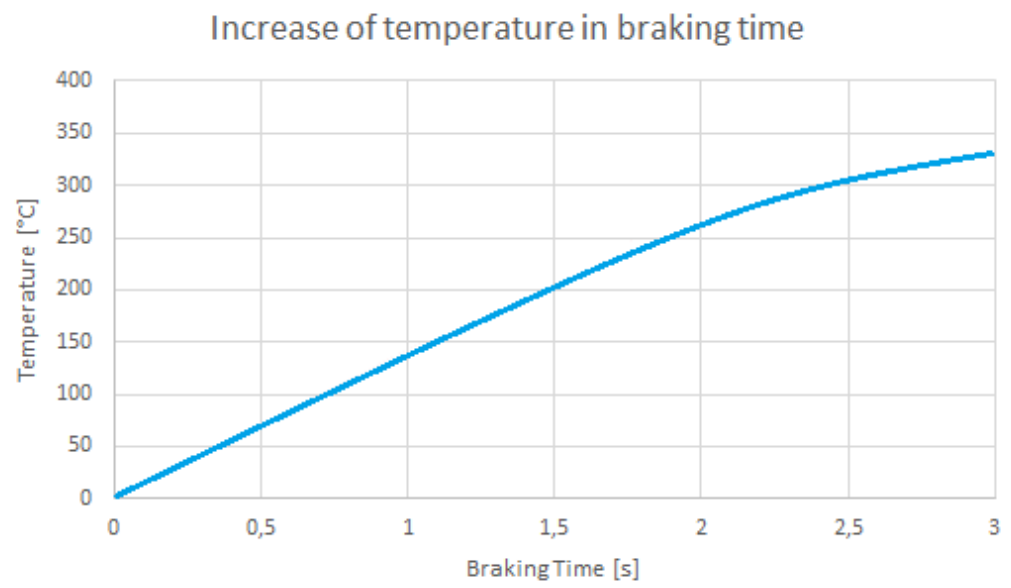

Fig. 6. Evolution of the maximum temperature of the disc

ments of the mesh in the entire unit amounted to nearly 12000 elements and almost 21500 nodes. The final operation involved generating a FE mesh in the entire three-dimensional solid fragment of the braking system, as shown in Figure 4.

The test object was prepared with numerical analysis in mind, taking account of considerable simplifications of the real model. This was however necessary to obtain approximate values of the dynamical results. Nowadays there is a relatively huge demand for specified regions of structural effort in terms of high temperatures. Given the constant development of structures and the potential of optimization, it is necessary to perform a series of numerical and experimental analyses in order to prevent and counteract overload during machinery operation. Numerical simulations enable predicting potential regions of material effort in structures due to temperature.

\section{RESULTS}

The FEM analysis enabled determination of high-temperature regions (in the form of a thermal trace) resulting from the applied rotational speed of the disk. In addition to this, the FEM analysis helped determine the temperature in the pads and, separately, in the disk. The simulation enabled visualization of the system's behavior and the effect of temperature. The figure 5 shows the FEM results for the initial instant of the analysis, as well as after 1, 2 and 3 seconds of the analysis.

The numerical results demonstrate the levels of temperatures generated due to the pressure on the disk from the brake pad due at the applied ro- tational speed. The spot of direct contact between the pads and the disk due to the applied pressure heats up very quickly, and, as a result, the temperature of the contact surface rapidly increases. At the initial instant of the analysis, following a half revolution of the disk at braking, the maximum temperature is $13.9^{\circ} \mathrm{C}$. After 1 second of the braking process the temperature is $141^{\circ} \mathrm{C}$, after 2 seconds it is $269^{\circ} \mathrm{C}$, after 3 seconds $332^{\circ} \mathrm{C}$. The relationship of increase of temperature in braking time is shown in Figure 6.

The temperature distribution in the radial direction in the third second of braking is shown in the Figure 7.

As the braking process continues, the disk heats up to a lesser and lesser degree, and the most temperature-affected region is the outer extreme region on the entire circumference of the disk in the spot of contact with the upper part of

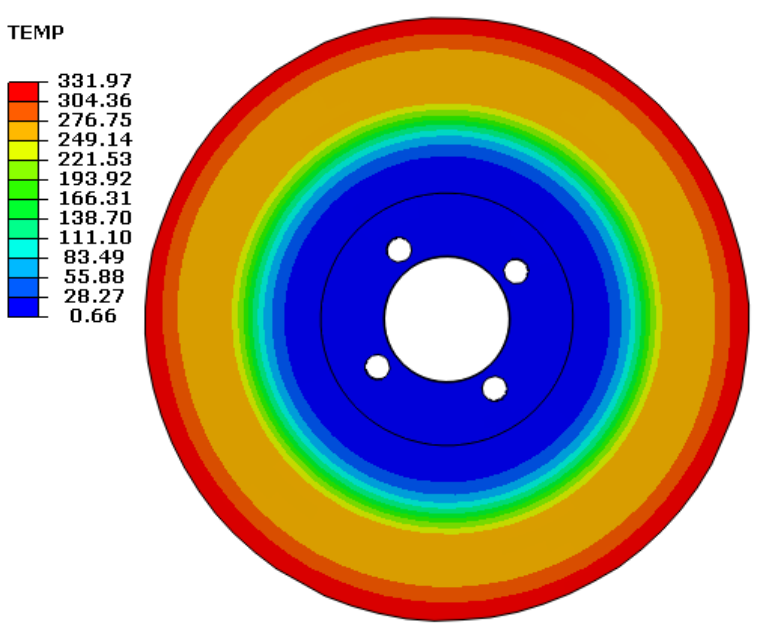

Fig. 7. Temperature distribution in the disc in time $=3 \mathrm{~s}$ 


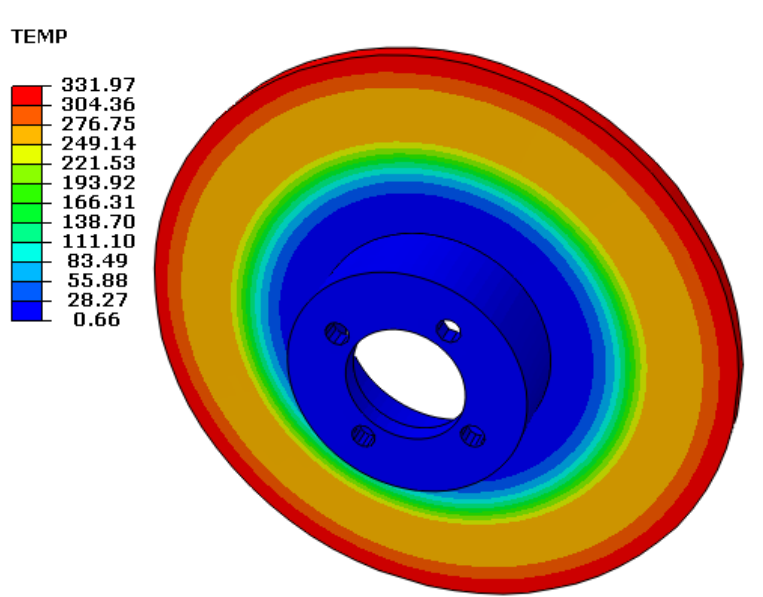

Fig. 8. Thermal analysis results for individual elements of the braking system: a) temperature in the disk, b) temperature in the pad

the pads. The investigation reflects the real work of the system, taking account of the regions that are most susceptible to high temperatures. The key aspect is to determine the direct regions which are susceptible to temperature, either in the disk or in the brake pads. The figure 8 shows the elements of the braking system. They are illustrated separately to visualize the distribution of temperatures in a correct way, after 3 seconds of the FEM analysis.

The numerical results demonstrate that it is necessary to conduct investigation on determining temperature of the braking system. The next stage of research on braking systems usually involves the use of suitable hollows, in the form of holes or empty spaces within the disk's structure in order to investigate efficient cooling of the structures. The consequence of designing braking systems is that mechanisms must be optimized with respect to their shape and topology in order to reduce weight and susceptibility to unfavorable temperature conditions.

\section{CONCLUSIONS}

The numerical analysis of the braking process for a car disk revealed a complex distribution of temperatures in the examined unit. The key aspect was to determine regions with the highest susceptibility to the temperature generated by friction between relevant planes. Owing to the use of materials reflecting those used in real braking system components, the FEM analysis enabled performing a simulation of the actual process. The aim of the study was to reflect the real braking process by a computer simulation. Numerical computer systems offer a great potential, and combined with the knowledge of physical process they can be used to recreate common daily-life phenomena, producing precise results. The results of the numerical analyses have led to the formulation of the following conclusions:

- it is possible to determine the degree of effect of temperature on the examined fragment of the braking system;

- it is possible to determine regions which are most susceptible to the effect of temperature during braking;

- the visualization of the braking process during the applied time ranges enables direct observation of the process of heating of the components due to the applied boundary conditions;

- the FEM results demonstrate that the disk is more susceptible to the effect of temperature than the brake pads by approximately $50 \%$;

- the maximum obtained temperature in the disk is connected with the region of the generated thermal track in the form of a ring and with a temperature of $332{ }^{\circ} \mathrm{C}$ during the third second of the analysis due to the pressure of the brake pads;

- It has been found that the heating of braking system gradually decreases with every another second of duration of the braking process.

Numerical environments enable realization of complex simulations which adequately reflect real physical phenomena. Further studies will focus on optimization of the braking system.

\section{REFERENCES}

1. Abaqus HTML Documentation.

2. Cheon J., Kiran D.V., Na S. J.: Thermal metallurgical analysis of GMA welded AH36 steel using CFDFEM framework. Materials and Design, 2016, 91, 230-241.

3. Ding H., Shen N., Shin Y. C.: Thermal and mechanical modeling analysis of laser-assisted micro-milling of difficult-to-machine alloys. Journal of Materials Processing Technology, 2012, 212, 601-613.

4. Example of brake disc: http://www.motorspeed. com.

5. Grzes P., Oliferuk W., Adamowicz A., Kochanowski K., Wasilewski P., Yevtushenko A.: The numerical-experimental scheme for the analysis of temperature field in a pad-disc braking system of a railway vehicle at single braking. International 
Communications in Heat and Mass Transfer, 2016, $75,1-6$.

6. Kardas O.O., Keles O., Akhtar S., Yilbas B.S.: Laser cutting of rectangular geometry in 2024 aluminum alloy: Thermal stress analysis. Optics \& Laser Technology, 2014, 64, 247-256.

7. Lonkwic P., Różyło P., Dębski H.: Numerical and experimental analysis of the progressive gear body with the use of finite-element method. Eksploatacja i Niezawodnosc - Maintenance and Reliability 2015, vol. 17 , no. 4, 544-550.

8. Lonkwic P., Rozylo P.: Theoretical and experimental analysis of loading impact from the progressive gear on the lift braking distance with the use of the free fall method. Advances in Science and Technology Research Journal, 10 (30), 2016, 103-109.

9. Meziane A., D'errico S., Baillet L., Laulagnet B.: Instabilities generated by friction in a pad-disc system during the braking process. Tribology International, (2007), vol 40, p.1127-1136.

10. Szmytka F., Salem M., Rézad'-Aria F., Oudin A.: Thermal fatigue analysis of automotive Diesel piston: Experimental procedure and numerical protocol. International Journal of Fatigue, 2015, vol. 73, 48-57.

11. Wu S.C., Zhang S.Q., Xu Z.W.: Thermal crack growth-based fatigue life prediction due to braking for a high-speed railway brake disc. International Journal of Fatigue, 2016, vol 87, 359-369.

12. Yevtushenko A.A., Grzes P.: The FEM-modeling of the frictional heating phenomenon in the pad/disc tribosystem (a review), Numerical Heat Transfer, Part A: Applications 2010, vol. 58, No. 3, 207-226.

13. Zienkiewicz O. C., Taylor R. L.: Finite Element Method (5th Edition) Volume 2 - Solid Mechanics, 2000, Elsevier. 